Article

\title{
Ultrasonic Assisted Extraction of Paclitaxel from Taxus $x$ media Using Ionic Liquids as Adjuvants: Optimization of the Process by Response Surface Methodology
}

\author{
Zhijian Tan ${ }^{1, *}$ (D), Qiao Li ${ }^{2}$, Chaoyun Wang ${ }^{1, *}$, Wanlai Zhou ${ }^{1}$, Yuanru Yang ${ }^{1}$, Hongying Wang ${ }^{1}$, \\ Yongjian $\mathrm{Yi}^{1}$ and Fenfang $\mathrm{Li}^{2}$ \\ 1 Institute of Bast Fiber Crops and Center of Southern Economic Crops, Chinese Academy of \\ Agricultural Sciences, Changsha 410205, China; aruofly@126.com (W.Z.); yangyuanru@caas.cn (Y.Y.); \\ Cswhy328@126.com (H.W.); ibfcyyj@163.com (Y.Y.) \\ 2 College of Chemistry and Chemical Engineering, Central South University, Changsha 410083, China; \\ liqiao@csu.edu.cn (Q.L.); lfflqq@csu.edu.cn (F.L.) \\ * Correspondence: tanzhijian@caas.cn or tanzhijiantgzy2010@aliyun.com (Z.T.); ibfcwcy@139.com (C.W.); \\ Tel.: +86-731-8899-8517 (Z.T.); Fax: +86-731-8899-8501 (C.W.)
}

Received: 1 August 2017; Accepted: 4 September 2017; Published: 11 September 2017

\begin{abstract}
Background: Ionic liquids (ILs) are considered "green" solvents and have been widely used in the extraction and separation field in recent years; (2) Methods: In this study, some common ILs and functionalized magnetic ionic liquids (MILs) were used as adjuvants for the solvent extraction of paclitaxel from Taxus $x$ media (T. $x$ media) using methanol solution. The extraction conditions of methanol concentration, IL type and amount, solid-liquid ratio, extraction temperature, and ultrasonic irradiation time were investigated in single factor experiments. Then, three factors of IL amount, solid-liquid ratio, and ultrasonic irradiation time were optimized by response surface methodology (RSM); (3) Results: The MIL $\left[\mathrm{C}_{4} \mathrm{MIM}\right] \mathrm{FeCl}_{3} \mathrm{Br}$ was screened as the optimal adjuvant. Under the optimization conditions of 1.2\% IL amount, 1:10.5 solid-liquid ratio, and 30 min ultrasonic irradiation time, the extraction yield reached $0.224 \mathrm{mg} / \mathrm{g}$; and (4) Conclusions: Compared with the conventional solvent extraction, this ultrasonic assisted extraction (UAE) using methanol and MIL as adjuvants can significantly improve the extraction yield, reduce the use of methanol, and shorten the extraction time, which has the potentiality of being used in the extraction of some other important bioactive compounds from natural plant resources.
\end{abstract}

Keywords: paclitaxel; ionic liquids; adjuvants; ultrasonic assisted extraction

\section{Introduction}

Paclitaxel $\left(\operatorname{Taxol}^{\circledR}\right)$ is a kind of terpene compound separated from various Taxus species. Due to its excellent anticancer effect, paclitaxel is currently the most widely used anticancer drug in clinical practice, including the curing of leukemia, ovarian cancer, breast cancer, Kaposi's sarcoma, and non-small cell lung cancer [1-3]. The demand of paclitaxel is becoming more and more great, however, the content of paclitaxel is very low (about $0.001-0.05 \%$ ) in dry Taxus samples, moreover, the Taxus species grow very slowly and are not abundant in the world $[4,5]$. Thus, how to obtain large amounts of paclitaxel is becoming a serious problem. There are multiple methods used for obtaining paclitaxel, for example, solvent extraction from the crude materials of Taxus or the plant cell cultures and the semi-synthesis from the precursors. Among these methods, the extraction of paclitaxel from crude materials using organic solvents is still a non-negligible method for obtaining paclitaxel due to the lower production cost and easier operation [3]. Nevertheless, in order to avoid the destruction of 
more Taxus trees, much work should be done, including the utilization of the branches on Taxus and improvement of the extraction efficiency by solvent extraction. It was reported that methanol was the optimal solvent used for the extraction of paclitaxel from Taxus among the commonly used organic solvents [6]. However, there are some disadvantages to solvent extraction, such as long extraction time, large quantities of methanol due to the low content of paclitaxel in bark, and the low extraction yield of paclitaxel.

Ionic liquids (ILs) are defined as molten salts which have melting points below or around $100{ }^{\circ} \mathrm{C}$. In recent years, ILs have been considered as one kind of green solvents due to their unique properties, including negligible volatility, low flammability, high thermal and chemical stability, excellent solubility ability, and potential recoverability [7-9]. Most importantly, ILs have tunable properties, whose cations and anions can be tailored to obtain various task-specific ILs with different physical and chemical properties $[10,11]$. Up to now, ILs were widely used in the extraction and separation of bioactive compounds from natural plant resources, such as extraction of caffeine from guaraná seeds [12], isoflavones from Radix puerariae [13], chlorogenic from Boehmerianivea L. Leaves [14], orientin and vitexin from the flowers of Trollius chinensis [15], caffeoylquinic acids from Flos Lonicerae Japonicae [16], and so on. Although the ILs were widely used in the extraction of bioactive compounds, their potential threat to the environment and human beings was underestimated, thus, the use of ILs deriving from natural products or some functionalized and recyclable ILs will be an inevitable trend [17,18].

As an effective method deriving from IL-based solid-liquid extraction, the extraction using ILs as adjuvants was also developed in recent years. The extraction efficiency can be obviously improved after addition of small amounts of adjuvants, such as the solvent extraction using organic solvents and aqueous two-phase extraction. For example, K.H. Row used ILs and deep eutectic solvents (DESs) as adjuvants for the extraction of astaxanthin from marine plants using acetone as the extraction solvent, the extraction can be obviously improved by addition of the adjuvants, meanwhile, the DESs had better performance than ILs [19]. J.A.P. Coutinho and co-workers used the ILs as adjuvants to improve the extraction and purification of immunoglobulin G in PEG/salt aqueous two-phase system [20].

In our previous work, it was found that the extraction using magnetic ionic liquids (MILs) as adjuvants to the salting-out extraction system can obtain higher extraction yield compared with no addition of ILs or addition of common ILs [21]. The MILs not only have the same properties to the common ILs, but also exhibit strong response to permanent magnetic field [22]. MILs have more advantages, such as overcoming of the formation of emulsions and the potentiality of being recovered in the presence of an external magnetic field, which has more potential application prospects than those of conventional ILs $[23,24]$. Due to these unique properties, MILs were used in the extraction and separation field, such as liquid-liquid extraction [25], dispersive liquid-liquid microextraction [26], aqueous two-phase extraction [27], and membrane separation [28]. Thus, the MILs are also feasible for use in the solid-liquid extraction in this work. The common ILs and MILs were used as adjuvants to the ultrasonic assisted extraction (UAE) of paclitaxel using methanol solution. The main factors influencing the extraction were investigated in the single factor experiments, and then the major factors were optimized by response surface methodology (RSM).

\section{Results and Discussion}

\subsection{Screening of the Optimal IL as Adjuvant}

In this work, eight imidazolium based ILs were considered as the adjuvants, including three common ILs and five functionalized MILs. It can be seen in Figure 1 that all the extraction yields were obviously improved after addition of ILs compared with the blank (no IL added). The extraction yield using ILs as adjuvants followed this order: No IL added $<[\mathrm{APMIM}] \mathrm{Cl}<[\mathrm{HOMIM}] \mathrm{FeCl}_{4} \approx\left[\mathrm{C}_{4} \mathrm{MIM}\right] \mathrm{Br}$ $<\left[\mathrm{C}_{8} \mathrm{MIM}\right] \mathrm{FeCl}{ }_{3} \mathrm{Br}<[\mathrm{HOMIM}] \mathrm{Cl} \approx\left[\mathrm{C}_{6} \mathrm{MIM}\right] \mathrm{FeCl}_{3} \mathrm{Br} \approx\left[\mathrm{C}_{2} \mathrm{MIM}\right] \mathrm{FeCl}_{3} \mathrm{Br}<\left[\mathrm{C}_{4} \mathrm{MIM}\right] \mathrm{FeCl}_{3} \mathrm{Br}$. It was reported that the extraction using ILs had been affected by multi-interactions including $\pi-\pi, n-\pi$, ionic/charge-charge, and hydrogen bonding between the target compounds and the extraction 
solvents [29]. The co-solvent was formed by methanol and IL; the IL had high polarity and the hydrogen-bond interaction occurred between paclitaxel and ILs, which is beneficial to the extraction. To analyze the results, it can be found that the influencing of cations in ILs was irregular, but the ILs with $\left[\mathrm{FeCl}_{3} \mathrm{Br}\right]^{-1}$ as anion had relatively higher extraction yields. The probable reason for this is the stronger $\pi-\pi$ interaction that occurred between paclitaxel and $\left[\mathrm{FeCl}_{3} \mathrm{Br}\right]^{-1}$ than that which occurred between paclitaxel and other anions. The maximum extraction yield can be obtained using $\left[\mathrm{C}_{4} \mathrm{MIM}\right] \mathrm{FeCl}_{3} \mathrm{Br}$ as the adjuvant. Moreover, it was reported that the acidic conditions were beneficial for the stability of paclitaxel [30], which can hydrolyze the 7-xylosyltaxol into paclitaxel leading to the increase of extraction yield [31]. The solution of $\left[\mathrm{C}_{4} \mathrm{MIM}\right] \mathrm{FeCl}_{3} \mathrm{Br}$ is acidic, thus, this MIL was chosen for further studies.

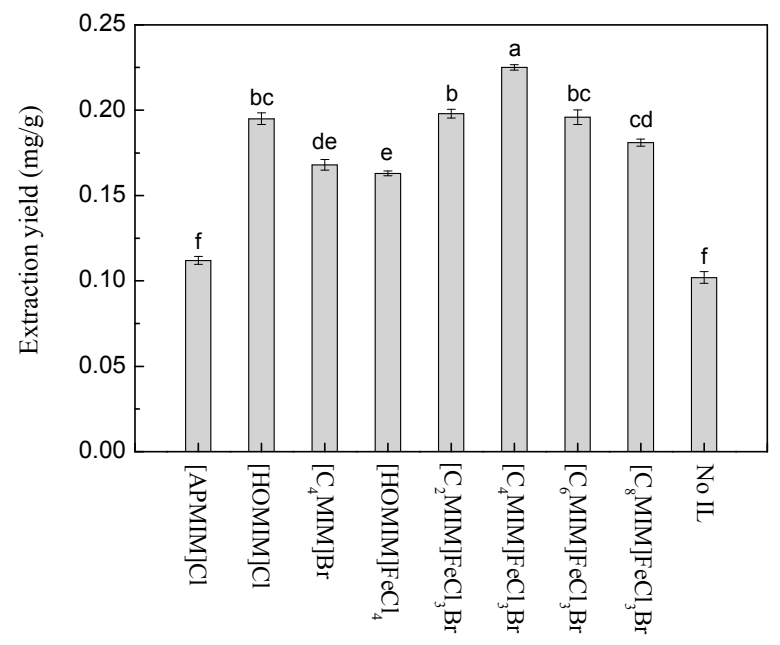

Figure 1. Effect of different ionic liquids (ILs) used as adjuvants to the extraction yields of paclitaxel (Extraction conditions: $0.5 \mathrm{~g}$ T. $x$ media leaves powder, $60 \mathrm{vol} \%$ methanol, $1.0 \mathrm{wt} \%$ IL added, 1:10 solid-liquid ratio, $40{ }^{\circ} \mathrm{C}$ extraction temperature, and $30 \mathrm{~min}$ ultrasonic irradiation time). Different letters in the same series indicate significant difference at $p<0.05$ level.

\subsection{Effect of IL Amount}

The effect of the IL amount was investigated at a range of 0.5-6.0 wt \%. The results in Figure 2a show that the maximum extraction yield was obtained when $1.0 \mathrm{wt} \%\left[\mathrm{C}_{4} \mathrm{MIM}\right] \mathrm{FeCl}_{3} \mathrm{Br}$ was added. The probable reason for the further increase of IL resulting in the decrease in extraction yield is that excess IL breaks the hydrogen-bond interaction between IL and methanol, making the polarity of this co-solvent decrease, which is not suitable for the extraction of paclitaxel. Therefore, $1.0 \mathrm{wt} \%$ $\left[\mathrm{C}_{4} \mathrm{MIM}\right] \mathrm{FeCl}_{3} \mathrm{Br}$ was chosen for further studies.

\subsection{Effect of Methanol Concentration}

Methanol concentration can be another factor influencing the extraction yield using this co-solvent formed by IL and methanol. Actually, there are many small molecule solvents, such as methanol, ethanol, acetone, dichloromethane, and trichloromethane, which were chosen for the extraction of paclitaxel from Taxus; methanol was proved to be the best solvent for the extraction among these solvents. Moreover, it was also reported that a high concentration of methanol $(>90 \%)$ was more beneficial for the extraction [32-34]. The effect of methanol concentration in the range of 50-90 vol \% was studied. The results in Figure $2 \mathrm{~b}$ show that the maximum extraction yield was obtained at the methanol concentration of $60 \mathrm{vol} \%$, then decreased with further increase of methanol concentration. The explanation of the increase of methanol concentration leading to the decrease in extraction yield is similar to that for the effect of $\mathrm{IL}$, the excess of methanol destroys the balance between IL and methanol making this co-solvent not beneficial to the extraction. The introduction of IL to this solvent 
extraction can obviously reduce the amount of methanol used. Thus, 60 vol \% methanol was chosen for further studies.

\subsection{Effect of Solid-Liquid Ratio}

The solid-liquid ratio can affect the extraction to some extent, less solvent leads to inadequate extraction, while excess solvent result in waste and an increase in cost. The solid-liquid ratio (mass of T. $x$ media leaves powder to the volume of co-solvent) in the ranges of 1:5, 1:10, 1:15, 1:20, and 1:25 was investigated. The results in Figure $2 c$ shows that the maximum extraction yield was obtained at the solid-liquid ratio of 1:10.Thisindicated that a proper solid-liquid ratio (for example 1:10) was enough for the extraction, while the high solid-liquid ratio (for example 1:5) led to inadequate extraction. The lower solid-liquid ratio (for example below 1:10) made the ultrasonic energy be absorbed and dispersed by a larger volume of solvent, which was disadvantageous for the UAE [35].

\subsection{Effect of Extraction Temperature}

Temperature is an important factor influencing the extraction. In a general way, the higher temperature can accelerate the mass transfer and diffusion, which is beneficial to the extraction. However, excessively high temperature will destroy the stability of some bioactive compounds. In this study, the effect of extraction temperature in the range of $20-60{ }^{\circ} \mathrm{C}$ was studied. The results in Figure $2 \mathrm{~d}$ show that the extraction yield increased with increase in temperature below $40{ }^{\circ} \mathrm{C}$, then decreased with further increment of temperature. The rise in temperature can increase solubility and facilitate paclitaxel diffusion by decreasing viscosity [36,37]. However, the higher temperature also caused degradation of paclitaxel; similar results were reported in other studies about the extraction of paclitaxel $[3,36]$. Thus, $40{ }^{\circ} \mathrm{C}$ was chosen as the optimal temperature.

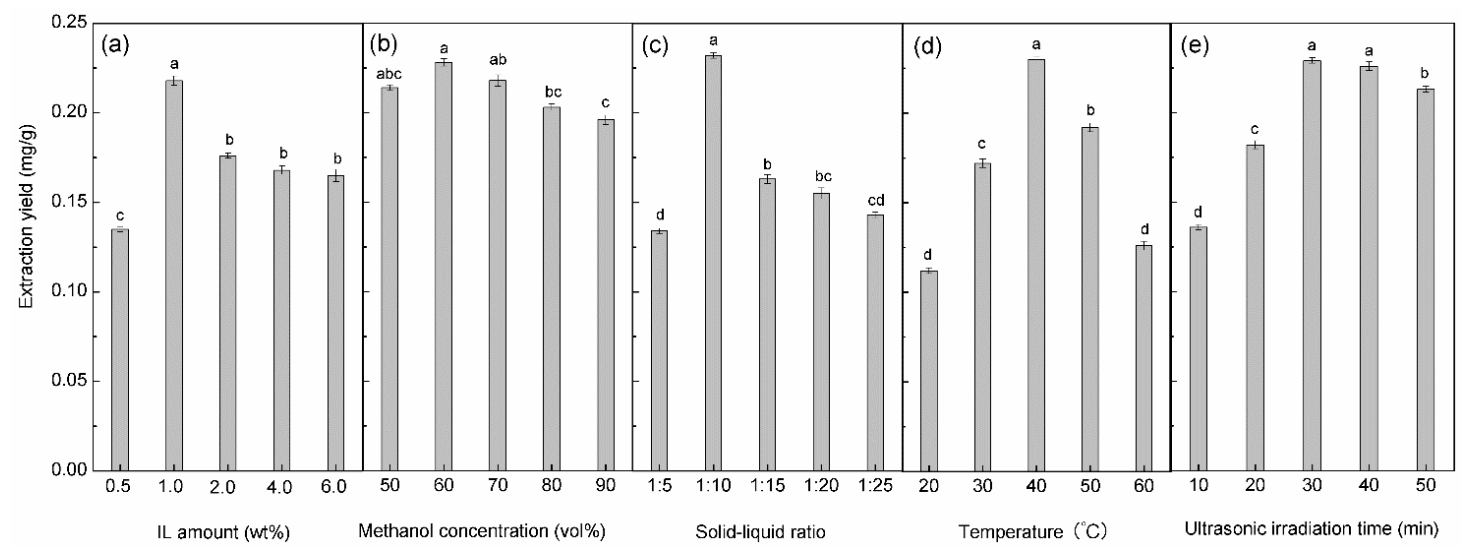

Figure 2. Effect of different factors to the extraction yield of paclitaxel in the single factor experiments. (a) the IL amount ( $0.5 \mathrm{~g}$ T. $x$ media leaves powder, $60 \mathrm{vol} \%$ methanol, $1: 10$ solid-liquid ratio, $40{ }^{\circ} \mathrm{C}$ extraction temperature, and 30 min extraction time); (b) Methanol concentration (0.5 g T. $x$ media leaves powder, $1.0 \mathrm{wt} \% \mathrm{IL}, 1: 10$ solid-liquid ratio, $40{ }^{\circ} \mathrm{C}$ extraction temperature, and $30 \mathrm{~min}$ ultrasonic irradiation time); (c) Solid-liquid ratio ( $0.5 \mathrm{~g}$ T. $x$ media leaves powder, $60 \mathrm{vol} \%$ methanol, $1.0 \mathrm{wt} \%$ $\mathrm{IL}, 40{ }^{\circ} \mathrm{C}$ extraction temperature, and $30 \mathrm{~min}$ ultrasonic irradiation time); (d) Extraction temperature ( $0.5 \mathrm{~g}$ T. $x$ media leaves powder, $60 \mathrm{vol} \%$ methanol, $1.0 \mathrm{wt} \% \mathrm{IL}, 1: 10$ solid-liquid ratio, and $30 \mathrm{~min}$ ultrasonic irradiation time); (e) Ultrasonic irradiation time (T. $x$ media leaves powder, $60 \mathrm{vol} \%$ methanol, $1.0 \mathrm{wt} \% \mathrm{IL}, 1: 10$ solid-liquid ratio, and $40{ }^{\circ} \mathrm{C}$ extraction temperature). Different letters in the same series indicate significant difference at $p<0.05$ level.

\subsection{Effect of Ultrasonic Irradiation Time}

It is well known that ultrasonic assisted extraction can shorten the extraction time compared with traditional heat reflux extraction. Thus, the ultrasonic irradiation time of 10-60 min was chosen in 
this study. It can be seen in Figure 2e that the extraction yield increased with ultrasonic irradiation time before $30 \mathrm{~min}$, then varied little with further increase of irradiation time, thus, the ultrasonic irradiation time of 30 min was chosen.

\subsection{Optimization of the Extraction by RSM}

Due to the shortage of analyses of the interaction between different factors influencing the extraction in single experiments, RSM based on Box-Behnken design (BBD) was used to evaluate the interaction between three major factors and optimize the extraction conditions. Three factors (IL amount, solid-liquid ratio, and ultrasonic irradiation time) and three levels (0.5, 1.0, and $1.5 \mathrm{wt} \%$ IL amount; 1:5, 1:10, and 1:15 solid-liquid ratio; and 20, 30, and 40 min ultrasonic irradiation time) were adopted to design the experiments. The list of experimental groups and the obtained results are shown in Table 1.

The ANOVA in Table 2 showed the $p$-value was $<0.0001$ and Model F-value was 154.83, which indicates the regression model and model are significant, respectively. There is a less than $0.01 \%$ probability that a "Model F-Value" occurs due to statistical noise. The model terms of A, B, A ${ }^{2}, B^{2}$, and $C^{2}$ were significant according to their $p$ values $<0.05$.

Table 1. Experimental results for the three-factor/three-level Box-Behnken design (BBD).

\begin{tabular}{ccccc}
\hline Runs & $\begin{array}{c}\text { Factor A: IL } \\
\text { Amount (wt \%) }\end{array}$ & $\begin{array}{c}\text { Factor B: } \\
\text { Solid-Liquid Ratio }\end{array}$ & $\begin{array}{c}\text { Factor C: Ultrasonic } \\
\text { Irradiation Time(min) }\end{array}$ & $\begin{array}{c}\text { Extraction } \\
\text { Yield (mg/g) }\end{array}$ \\
\hline 1 & 0.5 & $1: 5$ & 30 & 0.129 \\
2 & 1.5 & $1: 5$ & 30 & 0.176 \\
3 & 0.5 & $1: 15$ & 30 & 0.145 \\
4 & 1.5 & $1: 15$ & 30 & 0.186 \\
5 & 0.5 & $1: 10$ & 20 & 0.152 \\
6 & 1.5 & $1: 10$ & 20 & 0.198 \\
7 & 0.5 & $1: 10$ & 40 & 0.156 \\
8 & 1.5 & $1: 10$ & 40 & 0.201 \\
9 & 1.0 & $1: 5$ & 20 & 0.172 \\
10 & 1.0 & $1: 15$ & 20 & 0.183 \\
11 & 1.0 & $1: 5$ & 40 & 0.165 \\
12 & 1.0 & $1: 15$ & 40 & 0.186 \\
13 & 1.0 & $1: 10$ & 30 & 0.229 \\
14 & 1.0 & $1: 10$ & 30 & 0.224 \\
15 & 1.0 & $1: 10$ & 30 & 0.219 \\
16 & 1.0 & $1: 10$ & 30 & 0.227 \\
17 & 1.0 & $1: 10$ & 30 & 0.226 \\
\hline
\end{tabular}

Table 2. Analysis of variance (ANOVA) for the quadratic response surface model.

\begin{tabular}{cccccc}
\hline Source & Sum of Squares & Degree of Freedom & Mean Square & $\boldsymbol{F}$-Value & $\boldsymbol{p}$-Value Prob $>\boldsymbol{F}$ \\
\hline Model & $1.60 \times 10^{-2}$ & 9 & $1.742 \times 10^{-3}$ & 154.83 & $<0.0001$ \\
A & $4.005 \times 10^{-3}$ & 1 & $4.005 \times 10^{-3}$ & 356.01 & $<0.0001$ \\
B & $4.205 \times 10^{-4}$ & 1 & $4.205 \times 10^{-4}$ & 37.38 & 0.0005 \\
C & $1.125 \times 10^{-6}$ & 1 & $1.125 \times 10^{-6}$ & 0.10 & 0.7611 \\
AB & $9.00 \times 10^{-6}$ & 1 & $9.00 \times 10^{-6}$ & 0.80 & 0.4008 \\
AC & $2.50 \times 10^{-7}$ & 1 & $2.50 \times 10^{-7}$ & 0.022 & 0.8857 \\
BC & $2.50 \times 10^{-5}$ & 1 & $2.50 \times 10^{-5}$ & 2.22 & 0.1797 \\
A $^{2}$ & $4.551 \times 10^{-3}$ & 1 & $4.551 \times 10^{-3}$ & 404.50 & $<0.0001$ \\
B $^{2}$ & $4.62 \times 10^{-3}$ & 1 & $4.62 \times 10^{-3}$ & 410.67 & $<0.0001$ \\
C $^{2}$ & $9.953 \times 10^{-4}$ & 1 & $9.953 \times 10^{-4}$ & 88.47 & $<0.0001$ \\
Residual & $7.875 \times 10^{-5}$ & 7 & $1.125 \times 10^{-5}$ & & 0.7153 \\
Lack of Fit & $2.075 \times 10^{-5}$ & 3 & $6.917 \times 10^{-6}$ & 0.48 & \\
Pure Error & $5.8 \times 10^{-5}$ & 4 & $1.45 \times 10^{-5}$ & & \\
Cor Total & $1.61 \times 10^{-2}$ & 16 & & & \\
\hline
\end{tabular}


The "Lack of Fit F-value" of 0.48 implies the "Lack of Fit" is not significant relative to the pure error and that there is a $99.50 \%$ chance that a "Lack of Fit F-value" this large could occur due to noise. The regression model was generated by software, which was present in Equation (1):

$$
\begin{gathered}
\mathrm{Y}=0.22+0.022 \mathrm{~A}+7.25 \times 10^{-3} \mathrm{~B}+3.75 \times 10^{-4} \mathrm{C}-1.5 \times 10^{-3} \mathrm{AB}-2.5 \times 10^{-4} \mathrm{AC}+2.5 \times \\
10^{-3} \mathrm{BC}-0.033 \mathrm{~A}^{2}-0.033 \mathrm{~B}^{2}-0.015 \mathrm{C}^{2}\left(\mathrm{R}^{2}=0.9950\right)
\end{gathered}
$$

where $\mathrm{Y}$ is the extraction yield of paclitaxel ( $\mathrm{mg} / \mathrm{g}$ ), A is the IL amount (wt \%), B is the solid-liquid ratio, and $\mathrm{C}$ is ultrasonic irradiation time $(\mathrm{min})$. The coefficient of determination $\left(R^{2}\right)$ is 0.9950 , implying that more than $99.50 \%$ of the variations in the process efficiency could be explained by the model.

The response surfaces for the effects of the independent variables on the average extraction yield of paclitaxel $(\mathrm{mg} / \mathrm{g})$ are shown in Figure 3. The ordinate shows the extraction yields and the abscissa shows any two variables. The three-dimensional profiles can indicate how any two variables influence the extraction. It can be seen in Figure 3 that all the surfaces are upper convex with a maximum value at the center of the response surface, which approves the rationality of the predicted models [38]. The optimized conditions were obtained based on the quadratic model and are as follows: $1.17 \%$ IL amount $(w / w), 1: 10.51$ solid-liquid ratio, and 30.16 min ultrasonic irradiation time, giving a predicted extraction yield of $0.2292 \mathrm{mg} / \mathrm{g}$. The verification tests were done at the optimized conditions of $1.2 \% \mathrm{IL}$ amount, 1:10.5 solid-liquid ratio, and 30 min ultrasonic irradiation time. The experimental extraction yield with the average of triplicate runs was $0.224 \mathrm{mg} / \mathrm{g}$, which was close to the predicted value. The results demonstrate that the model is adequate for predicting the expected optimization.

(a)

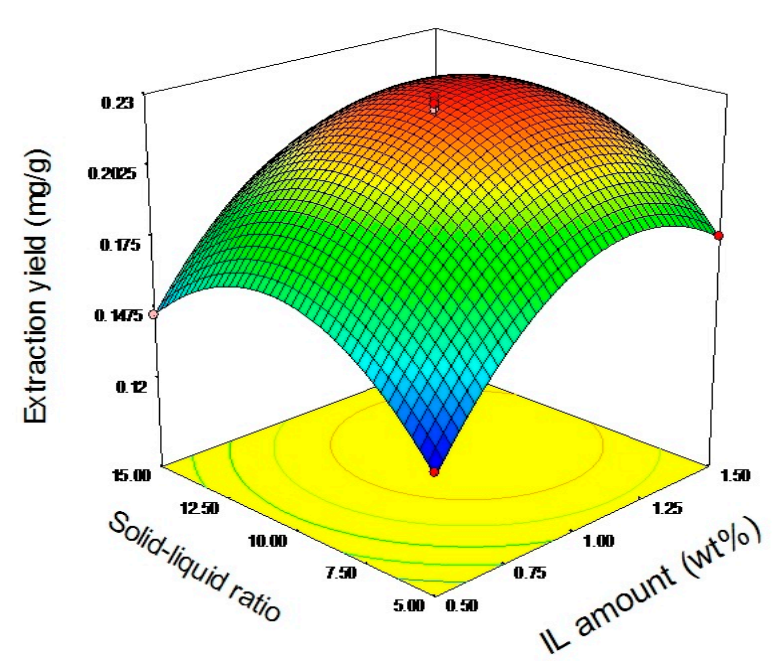

Figure 3. Cont. 
(b)

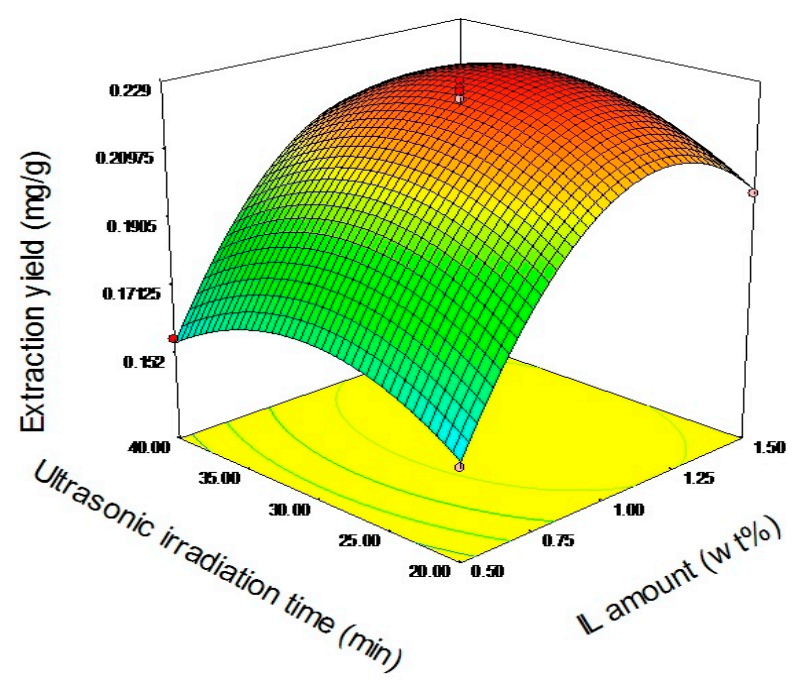

(c)

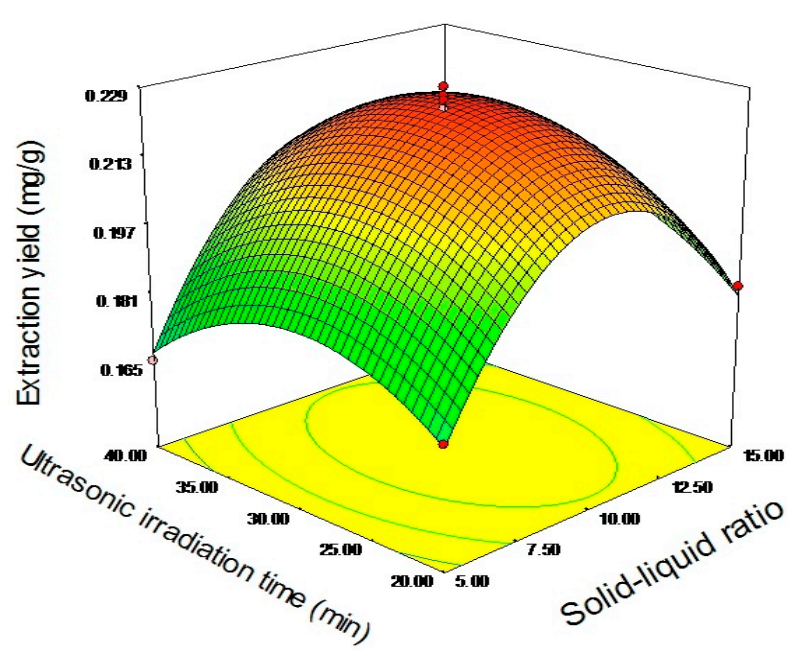

Figure 3. Response surface curves for the extraction of paclitaxel showing interaction between (a) IL amount (wt \%) and solid-liquid ratio; (b) IL amount (wt \%) and ultrasonic irradiation time (min), and (c) solid-liquid ratio and ultrasonic irradiation time $(\mathrm{min})$.

\section{Materials and Methods}

\subsection{Materials and Reagents}

The Taxus $x$ media leaves were obtained from Chongqing Beisheng Pharmachem Co. Ltd. (Chongqing, China). The leaves were harvested from the branches of the 20-year-old trees and dried in the drying oven with a constant temperature of $50{ }^{\circ} \mathrm{C}$. Then, the leaves were smashed to powder and sieved to 80 mesh particle size. The ILs $\left[\mathrm{C}_{2} \mathrm{MIM}\right] \mathrm{Br},\left[\mathrm{C}_{4} \mathrm{MIM}\right] \mathrm{Br},\left[\mathrm{C}_{6} \mathrm{MIM}\right] \mathrm{Br},\left[\mathrm{C}_{8} \mathrm{MIM}\right] \mathrm{Br}$, [APMIM]Cl, and [HOMIM]Cl were purchased from Shanghai Chengjie Chemical Co. Ltd. (Shanghai, China) with purity $>99 \%$. The other MILs of $[\mathrm{HOMIM}] \mathrm{FeCl}_{4},\left[\mathrm{C}_{8} \mathrm{MIM}\right] \mathrm{FeCl}_{3} \mathrm{Br}$, $\left[\mathrm{C}_{6} \mathrm{MIM}\right] \mathrm{FeCl}_{3} \mathrm{Br}$, $\left[\mathrm{C}_{2} \mathrm{MIM}\right] \mathrm{FeCl}_{3} \mathrm{Br}$, and $\left[\mathrm{C}_{4} \mathrm{MIM}\right] \mathrm{FeCl}_{3} \mathrm{Br}$ were synthesized according to the reported procedures by a simple exchange of anions. The structures of all the ILs used in this study are shown in Table 3, and the ILs were characterized by FT-IR spectroscopy and ${ }^{1} \mathrm{H}-\mathrm{NMR}$; the results proved that all synthesized ILs were target products. The paclitaxel standard with purity greater than $98 \%$ was purchased from 
Alladin Reagent Co., Ltd. (Shanghai, China). HPLC grade acetonitrile was obtained from TEDIA Company, Inc. (Fairfield, OH, USA). Methanol and ferric chloride of analytical grade were provided by Sinopharm Chemical Reagent Co., Ltd. (Shanghai, China). Other reagents were of analytical grade and used without further treatment. Deionized water was used to prepare the sample solutions.

Table 3. The full names and chemical structures of the ILs used in this study.

\begin{tabular}{l}
\hline Abbreviations of ILs (Full Names) \\
[APMIM]Cl \\
(1-aminopropyl-3-methylimidazolium chloride) \\
{$\left[\mathrm{C}_{2} \mathrm{OHMIM}\right] \mathrm{Cl}$} \\
(1-ethoxyl-3-methyl-imidazolium chloride) \\
{$\left[\mathrm{C}_{2} \mathrm{MIM}\right] \mathrm{Br}$ (1-ethyl-3-methyl-imidazolium } \\
bromide) \\
{$\left[\mathrm{C}_{2} \mathrm{OHMIM}\right] \mathrm{FeCl}$} \\
(1-ethoxyl-3-methyl-imidazolium \\
tetrachloroferrate) \\
{$\left[\mathrm{C}_{2} \mathrm{MIM}\right] \mathrm{FeCl}{ }_{3} \mathrm{Br}$ (1-ethyl-3-methyl-imidazolium } \\
bromotrichloroferrate) \\
{$\left[\mathrm{C}_{4} \mathrm{MIM}\right] \mathrm{FeCl}_{3} \mathrm{Br}$ (1-butyl-3-methyl-imidazolium } \\
bromotrichloroferrate) \\
{$\left[\mathrm{C}_{6} \mathrm{MIM}\right] \mathrm{FeCl}_{3} \mathrm{Br}$ (1-hexyl-3-methyl-imidazolium } \\
bromotrichloroferrate) \\
{$\left[\mathrm{C}_{8} \mathrm{MIM}\right] \mathrm{FeCl}_{3} \mathrm{Br}$ (1-octyl-3-methyl-imidazolium } \\
bromotrichloroferrate)
\end{tabular}

\subsection{Solvent Extraction of Paclitaxel}

To a tube, a certain amount of Taxus $x$ media leaves powder, methanol solution, and IL were added. The tube was placed in an ultrasonic bath (KQ-5200DE, Kunshan Ultrasound Co. Ltd., Kunshan, China) for the ultrasonic assisted extraction of paclitaxel. The operating conditions of the ultrasonic bath were as follow: $200 \mathrm{~W}$ electric power, $40 \mathrm{kHz}$ generators frequency, $50^{\circ} \mathrm{C}$ operating temperature, and $30 \mathrm{~min}$ ultrasonic irradiation time. The extract was centrifuged at $5000 \times g$ for $10 \mathrm{~min}$. The supernate was separated and diluted for the analysis of paclitaxel by HPLC. The extraction yield of paclitaxel was defined in the following Equation (2):

$$
\text { Extraction yield }(\mathrm{mg} / \mathrm{g})=\frac{\text { Mass of paclitaxel determined }(\mathrm{mg})}{\text { Mass of Taxusx media leaves powder }(\mathrm{g})}
$$

\subsection{HPLC Conditions}

A Dionex UltiMate 3000 HPLC system (Dionex, Sunnyvale, CA, USA) was equipped with a pump (model LPG-3400), a variable wavelength UV-Vis detector (model VWD-3400), and a RS column compartment (model TCC-3000). AKromasil 100-5- $\mathrm{C}_{18}$ reversed-phase chromatographic column $(250 \times 4.6 \mathrm{~mm}$ i.d., $5 \mu \mathrm{m})$ was used to analyze the samples. The mobile phase was acetonitrile-pure water $(60: 40, v / v)$. The flow rate was $1.0 \mathrm{~mL} / \mathrm{min}$ with isocratic elution. The effluent was monitored at the wavelength of $227 \mathrm{~nm}$ and the oven temperature was set at $28^{\circ} \mathrm{C}$. Each sample of $20 \mu \mathrm{L}$ was injected into the HPLC system. All the samples and mobile phase were filtered through microfiltration membrane $(0.45 \mu \mathrm{m})$ before analysis. The standard curve for analysis of paclitaxel is obtained in Equation (3):

$$
\mathrm{Y}=0.66204 \mathrm{X}-0.16951\left(\mathrm{r}^{2}=0.9998\right)
$$


where $\mathrm{Y}$ was the peak area and $\mathrm{X}$ was the concentration of standard paclitaxel with the linear range of 5.0-80 $\mu \mathrm{g} / \mathrm{mL}$. The HPLC chromatograms for paclitaxel extracted using methanol with and without addition of IL are shown in Figure 4.

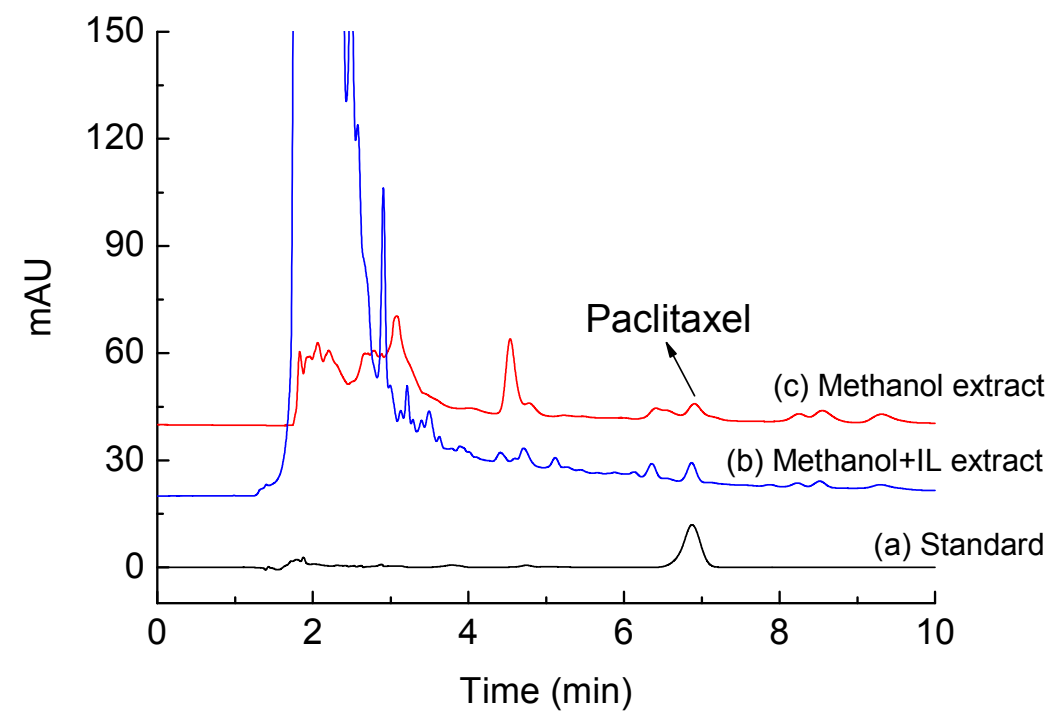

Figure 4. HPLC chromatograms for paclitaxel extracted from Taxus $x$ media leaves. (a) Standard; (b) methanol + IL extract; and (c) methanol extract.

\subsection{Statistical Analysis}

Design Expert 7.0 (DE, Stat-Ease, Inc., Minneapolis, MN, USA) was used to analyze the experimental data and obtain the response models. The values for coefficient of determination $\left(\mathrm{R}^{2}\right)$ and lack of fit were used to judge the suitability of the model. The analysis of variance (ANOVA) was carried out with the comparison of the experimental and predicted values. $p$ values $<0.05$ were considered statistically significant. The optimized conditions for the variables were acquired by statistical analysis. The statistical analysis for screening the ILs and single factor experiments was done using the Duncan's multiple range test. Each error bar indicates the standard deviation of triplicate tests.

\section{Conclusions}

In this work, the MIL $\left[\mathrm{C}_{4} \mathrm{MIM}\right] \mathrm{FeCl}_{3} \mathrm{Br}$ was used as the adjuvant to the ultrasonic assisted extraction of paclitaxel from T. $x$ media using methanol solution. The influencing factors of IL amount, methanol concentration, solid-liquid ratio, extraction temperature, and ultrasonic irradiation time in single factor experiments were investigated. Then, the major factors of IL amount, solid-liquid ratio, and ultrasonic irradiation time were optimized by RSM. The extraction yield reached $0.224 \mathrm{mg} / \mathrm{g}$ under the optimized conditions of 1.2\% IL amount, 1:10.5 solid-liquid ratio, and 30 min ultrasonic irradiation time. Compared with conventional solvent extraction, this ultrasonic assisted extraction using ILs as adjuvants can reduce the usage of methanol, shorten the extraction time, and raise the extraction yield, which has the prospect for application in the extraction of some important bioactive compounds from natural plants.

Acknowledgments: This work was financially supported by the National Natural Science Foundation of China (No. 21406262), Central Public-interest Scientific Institution Basal Research Fund (No. 1610242016006), and the Agricultural Science and Technology Innovation Program (No. ASTIP-IBFC07).

Author Contributions: Zhijian Tan, Chaoyun Wang, and Fenfang Li conceived and designed the experiments; Qiao Li, Yuanru Yang, Wanlai Zhou, Yongjian Yi, and Hongying Wang performed the experiments; Zhijian Tan and Yuanru Yang analyzed the data; Zhijian Tan wrote and revised the paper. 
Conflicts of Interest: The authors declare no conflict of interest.

\section{References}

1. Taura, K.; Yamamoto, S.; Hayashi, S.; Shioya, S. Enhanced paclitaxel production by addition of water-soluble 5-aminolevulinic acid and in situ extraction with lauryl alcohol in a suspension callus culture. Solvent Extr. Res. Dev. 2013, 20, 65-70. [CrossRef]

2. Lee, J.Y.; Kim, J.H. Effect of water content of organic solvent on microwave-assisted extraction efficiency of paclitaxel from plant cell culture. Korean J. Chem. Eng. 2011, 28, 1561-1565. [CrossRef]

3. Zu, Y.; Wang, Y.; Fu, Y.; Li, S.; Sun, R.; Liu, W.; Luo, H. Enzyme-assisted extraction of paclitaxel and related taxanes from needles of taxuschinensis. Sep. Purif. Technol. 2009, 68, 238-243. [CrossRef]

4. Wu, J.; Lin, L. Enhancement of taxol production and release in taxuschinensis cell cultures by ultrasound, methyl jasmonate and in situ solvent extraction. Appl. Microbiol. Biot. 2003, 62, 151-155. [CrossRef] [PubMed]

5. Dong, H.; Luo, L.; Bi, P.; Zheng, Y.; Zhao, J. Determination of taxol, cephalomannine and 7-epi-taxol in taxus by prp-6 solid phase extraction and high performance liquid chromatography. Anal. Lett. 2005, 38, 929-937. [CrossRef]

6. Ketchum, R.E.B.; Luong, J.V.; Gibson, D.M. Efficient extraction of paclitaxel and related taxoids from leaf tissue of taxus using a potable solvent system. J. Liq. Chromatogr. Relat. Technol. 1999, 22, 1715-1732. [CrossRef]

7. Huddleston, J.G.; Willauer, H.D.; Swatloski, R.P.; Visser, A.E.; Rogers, R.D. Room temperature ionic liquids as novel media for "Clean" Liquid-liquid extraction. Chem. Commun. 1998, 1765-1766. [CrossRef]

8. Rogers, R.D.; Seddon, K.R. Ionic liquids-solvents of the future? Science 2003, 302, 792-793. [CrossRef] [PubMed]

9. Ho, T.D.; Zhang, C.; Hantao, L.W.; Anderson, J.L. Ionic liquids in analytical chemistry: Fundamentals, advances, and perspectives. Anal. Chem. 2013, 86, 262-285. [CrossRef] [PubMed]

10. Lee, S.-G. Functionalized imidazolium salts for task-specific ionic liquids and their applications. Chem. Commun. 2006, 1049-1063. [CrossRef] [PubMed]

11. Giernoth, R. Task-specific ionic liquids. Angew. Chem. Int. Ed. 2010, 49, 2834-2839. [CrossRef] [PubMed]

12. Claudio, A.F.M.; Ferreira, A.M.; Freire, M.G.; Coutinho, J.A.P. Enhanced extraction of caffeine from guarana seeds using aqueous solutions of ionic liquids. Green Chem. 2013, 15, 2002-2010. [CrossRef]

13. Zhang, Y.; Liu, Z.; Li, Y.; Chi, R. Optimization of ionic liquid-based microwave-assisted extraction of isoflavones from radix puerariae by response surface methodology. Sep. Purif. Technol. 2014, 135, 285. [CrossRef]

14. Yang, Z.; Tan, Z.; Li, F.; Li, X. An effective method for the extraction and purification of chlorogenic acid from ramie (boehmerianivea 1.) leaves using acidic ionic liquids. Ind. Crop Prod. 2016, 89, 78-86. [CrossRef]

15. Chen, F.; Zhang, Q.; Mo, K.; Fei, S.; Gu, H.; Yang, L. Optimization of ionic liquid-based homogenate extraction of orientin and vitexin from the flowers of trolliuschinensis and its application on a pilot scale. Sep. Purif. Technol. 2017, 175, 147-157. [CrossRef]

16. Tan, T.; Lai, C.J.S.; OuYang, H.; He, M.Z.; Feng, Y. Ionic liquid-based ultrasound-assisted extraction and aqueous two-phase system for analysis of caffeoylquinic acids from flosloniceraejaponicae. J. Pharmaceut. Biomed. 2016, 120, 134-141. [CrossRef] [PubMed]

17. Fukumoto, K.; Yoshizawa, M.; Ohno, H. Room temperature ionic liquids from 20 natural amino acids. J. Am. Chem. Soc. 2005, 127, 2398-2399. [CrossRef] [PubMed]

18. Bubalo, M.C.; Radosevic, K.; Redovnikovic, I.R.; Halambek, J.; Srcek, V.G. A brief overview of the potential environmental hazards of ionic liquids. Ecotoxicol. Environ. Safe 2014, 99, 1-12. [CrossRef] [PubMed]

19. Lee, Y.R.; Row, K.H. Comparison of ionic liquids and deep eutectic solvents as additives for the ultrasonic extraction of astaxanthin from marine plants. J. Ind. Eng. Chem. 2016, 39, 87-92. [CrossRef]

20. Ferreira, A.M.; Faustino, V.F.M.; Mondal, D.; Coutinho, J.A.P.; Freire, M.G. Improving the extraction and purification of immunoglobulin $\mathrm{g}$ by the use of ionic liquids as adjuvants in aqueous biphasic systems. J. Biotechnol. 2016, 236, 166-175. [CrossRef] [PubMed]

21. Li, F.; Li, Q.; Wu, S.; Sun, D.; Tan, Z. Salting-out extraction of sinomenine from sinomeniumacutum by an alcohol/salt aqueous two-phase system using ionic liquids as additives. J. Chem. Technol. Biot. 2017. [CrossRef] 
22. Wang, J.; Yao, H.; Nie, Y.; Bai, L.; Zhang, X.; Li, J. Application of iron-containing magnetic ionic liquids in extraction process of coal direct liquefaction residues. Ind. Eng. Chem. Res. 2012, 51, 3776-3782. [CrossRef]

23. Wang, J.; Yao, H.; Nie, Y.; Zhang, X.; Li, J. Synthesis and characterization of the iron-containing magnetic ionic liquids. J. Mol. Liq. 2012, 169, 152-155. [CrossRef]

24. Santos, E.; Albo, J.; Irabien, A. Magnetic ionic liquids: Synthesis, properties and applications. RSC Adv. 2014, 4, 40008-40018. [CrossRef]

25. Deng, N.; Li, M.; Zhao, L.; Lu, C.; De Rooy, S.L.; Warner, I.M. Highly efficient extraction of phenolic compounds by use of magnetic room temperature ionic liquids for environmental remediation. J. Hazard. Mater. 2011, 192, 1350-1357. [CrossRef] [PubMed]

26. Wang, Y.; Sun, Y.; Xu, B.; Li, X.; Jin, R.; Zhang, H.; Song, D. Magnetic ionic liquid-based dispersive liquid-liquid microextraction for the determination of triazine herbicides in vegetable oils by liquid chromatography. J. Chromatogr. A 2014, 1373, 9-16. [CrossRef] [PubMed]

27. Yao, T.; Yao, S. Magnetic ionic liquid aqueous two-phase system coupled with high performance liquid chromatography: A rapid approach for determination of chloramphenicol in water environment. J. Chromatogr. A 2017, 1481, 12-22. [CrossRef] [PubMed]

28. Albo, J.; Santos, E.; Neves, L.A.; Simeonov, S.P.; Afonso, C.A.M.; Crespo, J.G.; Irabien, A. Separation performance of $\mathrm{co} 2$ through supported magnetic ionic liquid membranes (smilms). Sep. Purif. Technol. 2012, 97, 26-33. [CrossRef]

29. Bogdanov, M.G. Ionic liquids as alternative solvents for extraction of natural products. In Alternative Solvents for Natural Products Extraction; Chemat, F., Abert-Vian, M., Eds.; Springer: Berlin, Germany; Heidelberg, Germany, 2014; pp. 127-166.

30. McPartland, T.J.; Patil, R.A.; Malone, M.F.; Roberts, S.C. Liquid-liquid extraction for recovery of paclitaxel from plant cell culture: Solvent evaluation and use of extractants for partitioning and selectivity. Biotechnol. Prog. 2012, 28, 990-997. [CrossRef] [PubMed]

31. Choi, H.K.; Son, J.S.; Na, G.H.; Hong, S.S.; Park, Y.S.; Song, J.Y. Mass production of paclitaxel by plant cell culture. J. Plant Biotechnol. 2002, 29, 59-62. [CrossRef]

32. Kim, G.J.; Kim, J.H. A simultaneous microwave-assisted extraction and adsorbent treatment process under acidic conditions for recovery and separation of paclitaxel from plant cell cultures. Korean J. Chem. Eng. 2015, 32, 1023-1028. [CrossRef]

33. Kawamura, F.; Kikuchi, Y.; Ohira, T.; Yatagai, M. Accelerated solvent extraction of paclitaxel and related compounds from the bark of taxuscuspidata. J. Nat. Prod. 1999, 62, 244-247. [CrossRef] [PubMed]

34. Kim, G.J.; Kim, J.H. Enhancement of extraction efficiency of paclitaxel from biomass using ionic liquid-methanol co-solvents under acidic conditions. Process Biochem. 2015, 50, 989-996. [CrossRef]

35. Lin, H.; Zhang, Y.; Han, M.; Yang, L. Aqueous ionic liquid based ultrasonic assisted extraction of eight ginsenosides from ginseng root. Ultrason. Sonochem. 2013, 20, 680-684. [CrossRef] [PubMed]

36. Ha, G.S.; Kim, J.H. Kinetic and thermodynamic characteristics of ultrasound-assisted extraction for recovery of paclitaxel from biomass. Process Biochem. 2016, 51, 1664-1673. [CrossRef]

37. Kim, T.W.; Kim, J.H. Kinetics and thermodynamics of paclitaxel extraction from plant cell culture. Korean J. Chem. Eng. 2016, 33, 3175-3183. [CrossRef]

38. Fan, J.P.; Cao, J.; Zhang, X.H.; Huang, J.Z.; Kong, T.; Tong, S.; Tian, Z.Y.; Xie, Y.L.; Xu, R.; Zhu, J.H. Optimization of ionic liquid based ultrasonic assisted extraction of puerarin from radix puerariaelobatae by response surface methodology. Food Chem. 2012, 135, 2299-2306. [CrossRef] [PubMed]

Sample Availability: Samples of the compounds paclitaxel from Taxus $x$ media leaves are available from the authors.

(C) 2017 by the authors. Licensee MDPI, Basel, Switzerland. This article is an open access article distributed under the terms and conditions of the Creative Commons Attribution (CC BY) license (http:/ / creativecommons.org/licenses/by/4.0/). 